University of Wollongong

Research Online

Faculty of Engineering and Information

Faculty of Engineering and Information

Sciences - Papers: Part A

Sciences

$1-1-2016$

Persuasive technology in mobile applications promoting physical activity: a systematic review

John Matthews

University of Wollongong, jfm806@uowmail.edu.au

Khin Than Win

University of Wollongong, win@uow.edu.au

Harri Oinas-Kukkonen

University of Oulu

Mark Freeman

University of Wollongong, mfreeman@uow.edu.au

Follow this and additional works at: https://ro.uow.edu.au/eispapers

Part of the Engineering Commons, and the Science and Technology Studies Commons

Research Online is the open access institutional repository for the University of Wollongong. For further information contact the UOW Library: research-pubs@uow.edu.au 


\title{
Persuasive technology in mobile applications promoting physical activity: a systematic review
}

\begin{abstract}
Persuasive technology in mobile applications can be used to influence the behaviour of users. A framework known as the Persuasive Systems Design model has been developed for designing and evaluating systems that influence the attitudes or behaviours of users. This paper reviews the current state of mobile applications for health behavioural change with an emphasis on applications that promote physical activity. The inbuilt persuasive features of mobile applications were evaluated using the Persuasive Systems Design model. A database search was conducted to identify relevant articles. Articles were then reviewed using the Persuasive Systems Design model as a framework for analysis. Primary task support, dialogue support, and social support were found to be moderately represented in the selected articles. However, system credibility support was found to have only low levels of representation as a persuasive systems design feature in mobile applications for supporting physical activity. To ensure that available mobile technology resources are best used to improve the wellbeing of people, it is important that the design principles that influence the effectiveness of persuasive technology be understood.
\end{abstract}

\section{Keywords}

review, activity, physical, promoting, applications, mobile, technology, systematic, persuasive

\section{Disciplines}

Engineering | Science and Technology Studies

\section{Publication Details}

Matthews, J., Win, K., Oinas-Kukkonen, H. \& Freeman, M. (2016). Persuasive technology in mobile applications promoting physical activity: a systematic review. Journal of Medical Systems, 40 (3), 72-85. 


\section{Persuasive Technology in Mobile Applications Promoting Physical Activity: A Systematic Review}

John Matthews, Khin Than Win, Harri Oinas-Kukkonen, Mark Freeman

John Matthews

jfm806@uowmail.edu.au

School of Computing and Information Technology

University of Wollongong

Khin Than Win

win@uow.edu.au

School of Computing and Information Technology

University of Wollongong

Harri Oinas-Kukkonen

Harri.oinas-kukkonen@oulu.fi

University of Oulu

Finland

Mark Freeman

mfreeman@uow.edu.au

School of Computing and Information Technology

University of Wollongong

Corresponding author

Associate Professor Khin Than Win

win@uow.edu.au

School of Computing and Information Technology

University of Wollongong

Northfields Avenue, Wollongong 2522

Australia

Tel: 61242214142 


\begin{abstract}
Persuasive technology in mobile applications can be used to influence the behaviour of users. A framework known as the Persuasive Systems Design model has been developed for designing and evaluating systems that influence the attitudes or behaviours of users. This paper reviews the current state of mobile applications for health behavioural change with an emphasis on applications that promote physical activity. The inbuilt persuasive features of mobile applications were evaluated using the Persuasive Systems Design model. A database search was conducted to identify relevant articles. Articles were then reviewed using the Persuasive Systems Design model as a framework for analysis. Primary task support, dialogue support, and social support were found to be moderately represented in the selected articles. However, system credibility support was found to have only low levels of representation as a persuasive systems design feature in mobile applications for supporting physical activity. To ensure that available mobile technology resources are best used to improve the wellbeing of people, it is important that the design principles that influence the effectiveness of persuasive technology be understood.
\end{abstract}

\title{
Keywords
}

Persuasive technology

Behaviour modification

Mobile Application

Health Education

Physical Activity

\section{Introduction}

The growing impact of mobile health applications to inform, educate and persuade consumers should not be underestimated. The nature of these systems is such that they can have far reaching impact on people and communities that may not otherwise have access to suitable health education resources. To ensure that this expanding field is developed to its greatest potential, we must strive to fully understand how the available mobile technology resources can best be used to improve the wellbeing of people. It is especially important for government 
endeavours that the design principles that influence the effectiveness of persuasive technology be understood.

Lifestyle modification is an important feature of chronic disease management. Physical activity is one aspect of lifestyle modifications that could be an effective tool in reducing rates of hospital admission and reducing risk of mortality. Increasing physical activity to low or moderate levels can result in lower risk of mortality from all causes [1]. Worldwide $31.1 \%$ of adults are categorised as inactive, ranging from $17 \%$ in Southeast Asia to $43 \%$ in the Americas and the eastern Mediterranean [2]. This level of inactivity is inconsistent with the levels of physical activity required to maintain good health. To promote and maintain health it is recommended that healthy adults engage in moderate-intensity physical activity for 30 minutes on five days of each week [3].

The prevalence of non-communicable disease such as cardiovascular conditions, respiratory conditions, and type 2 diabetes has increased worldwide; with $60 \%$ of total mortality being attributed to non-communicable diseases globally [3]. Although there are numerous causes of non-communicable disease, physical inactivity can account for a significant share of this burden. For example, Lee et al. [4] found that physical inactivity is responsible for $6 \%$ of the burden of disease from heart disease, $7 \%$ of type 2 diabetes, and $10 \%$ of breast cancer and $10 \%$ of colon cancer. In total, physical inactivity is responsible for $9 \%$ of all premature mortality [4]. Studies indicate that interactive computing could change consumers' attitudes and behaviour with regard to their healthcare management [5] as this could reach a wider audience. Studies in Australia indicated that the rural population is physically less active than its urban counterpart due to limited accessibility to services and facilities [6]. Morgan et al. also noted in their study that face-to-face programs for weight management are less attractive to men [7]. Effectiveness of the Internet in modification of consumer behaviour has also been reported in previous studies [5,8-11]. Advances in mobile technology may provide some solutions to global health issues caused by physical inactivity. The developing field of Mobile Health provides an opportunity to improve disease prevention and management through the use of mobile technology [12]. The increasing prevalence of smartphones and an increase worldwide in Internet 
access suggests that mobile technology could play an increasingly significant role in health education in the future. There is considerable potential for healthcare and clinical intervention to be transformed by mobile technologies [13].

Prior research has identified that information systems can be used to influence the behaviour of users. Context plays an important role in influencing behaviour by persuasion. Persuasion of users to improve physical activity would be different from persuading users to take medication or cease smoking. Behaviour techniques that should be used in persuasion include engaging the patient in interactive conversation. Therefore, persuasive systems should mimic or extend the patientprovider communication [14]. Moreover, information provided should be from a trustworthy source. Online information provision needs to be credible to consumers [15]. Several researchers have studied the tailoring of systems according to the users' needs [16-19], providing interactivity of the system for better communication [20-22], and social support [23,24]. A framework known as the Persuasive Systems Design (PSD) model has been developed for designing and evaluating systems that influence the attitudes or behaviours of users [10]. The model describes seven postulates that need to be addressed when designing or evaluating persuasive systems. These postulates relate to the users of persuasive systems, persuasion strategies, and system features. In addition to this, the model defines twenty-eight design guidelines. The guidelines describe system features that will improve the persuasiveness of a system. The system features are divided into four categories: primary task support, dialogue support, system credibility support, and social support. For persuasive systems features and categories, see Appendix A.

Persuasive technologies in mobile applications promoting physical activity are becoming increasingly prevalent as access to smartphone technology increases. Mobile applications are being developed that incorporate numerous persuasive design features that are being used to modify the behaviour of users. These applications are continually improving and are being used more and more by people in their daily lives. Individuals are being motivated and inspired to achieve their fitness goals and improve their wellbeing. Although several applications such as Nike[10] and other applications have been seen, there is a lack of 
comprehensive reviews on the design features. By utilizing the theory based framework PSD, this study will review the persuasive features of current applications available. The results from this study will identify the emphasis, gaps and commonly present design features in mobile application for motivating physical activity.

This article aims to review current state of mobile applications for health behavioural change with an emphasis on applications that promote physical activity. The inbuilt persuasive features of these applications will be evaluated using the PSD model.

\section{Methods}

\section{Literature Search}

A database search was conducted to identify relevant articles using the online database Scopus. The search was conducted in December 2014 and targeted articles published from 2005 through to 2014. A keyword search limited to the article title, abstract and key words was performed using the following search string: (mobile OR “smart phone” OR smartphone OR wireless OR handheld) AND (persua* OR ((behaviour* OR behaviour*) AND (influen* OR modif* OR chang*))) AND (“physical activity” OR mhealth* OR health* OR exercise OR wellness OR fitness).

\section{Inclusion and Exclusion Criteria}

To be considered for inclusion in the review, articles were required to meet the following criteria. Firstly, publication in a peer reviewed academic journal or peer reviewed report from an international scientific conference. Secondly, the article must discuss mobile applications intended for use on a smartphone or similar wireless mobile device. Thirdly, the article must be related to the design features that promote physical activity, for example reducing sedentary behaviour or encouraging exercise. Articles that focused on other forms of behavioural modification such as smoking cessation, nutritional intervention, or medication adherence were excluded from the review. 


\section{Data Extraction}

Using the inclusion and exclusion criteria previously outlined, a suitable number of articles were identified for further analysis. These articles were then reviewed using the PSD model as a framework for analysis. Data extraction and coding were conducted through two researchers reading through these articles, identifying quotes applicable to design features, and coding them in an excel spreadsheet. The persuasive design features were extracted in four categories: primary task support, dialogue support, system credibility support, and social support. Each of these categories was further divided into seven sub-categories. Coding discrepancies and interpretations were identified and discussed, involving all authors and final coding was presented after the consensus. The data extraction process is presented in figure 1 . Figure 2 presents the design features present in each category. Figure 3 presents the mapping of the design features in each category. 




Figure 1: Data extraction

\section{Results}

The database search yielded 1366 unique, potentially relevant articles. From this set of articles, 1134 were excluded on the basis that the article title did not meet the inclusion criteria. Of the remaining 232 articles, a further 196 were excluded on the basis of the article abstract. The full text of the remaining 36 articles was assessed and 16 articles were excluded on the basis that the article did not provide sufficient examination of persuasive design features. The resulting 20 articles were included in the review. Eleven of those articles were randomized controlled 
trial or outcome studies, five articles focused on software design and evaluation and the remaining articles are on focus groups and interview studies on stakeholders’ opinions on smart phone apps for physical activity (see Table 1).

Table 1 Study type in reviewed articles

\begin{tabular}{|l|l|}
\hline Antpas 2014 & Focus group, intervention design \\
\hline Artega et al. 2010 & Prototype development \\
\hline Ayubi \& Parmanto & $\begin{array}{l}\text { System development, Persuasive social } \\
\text { network for physical activity }\end{array}$ \\
\hline Bond et al. 2014 & $\begin{array}{l}\text { B-mobile, smart phone based outcome } \\
\text { study }\end{array}$ \\
\hline Chang et al. 2012 & User decisions for app use \\
\hline Dantzig et al. 2013 & $\begin{array}{l}\text { Randomised controlled trial for app and } \\
\text { feedback }\end{array}$ \\
\hline Dennison 2014 & Focus group on smart phone app support \\
life style
\end{tabular}


Table 2 Persuasive design principles present in reviewed articles

\begin{tabular}{|l|l|l|l|l|l|l|l|l|l|l|l|l|l|l|l|l|l|l|l|}
\hline \multicolumn{2}{|c|}{$\begin{array}{c}\text { Primary Task } \\
\text { Support }\end{array}$} \\
\hline
\end{tabular}

Illustrations in figure 2 and table 2 show features that are highly present in articles on physical activity intervention studies, those features that were occasionally mentioned, or those that were not cited often in these articles. Visualisation of persuasive features is presented to provide more insights about the highlights, 
gaps and blank spots [45] in current mobile application persuasive design features on physical activity. Figure 2 shows the bar chart to present a visual indication of each category of persuasive features present in reviewed articles. Figure 3 illustrates the map of persuasive design features in dyad. The structure of dyadic association among persuasive feature categories is displayed. The top left triangular submatrix displays the dyads among the primary task support feature. The submatrix below that represents the association among primary task support and dialogue support features, and so on.



Figure 2: Frequency of persuasive features present in reviewed articles 


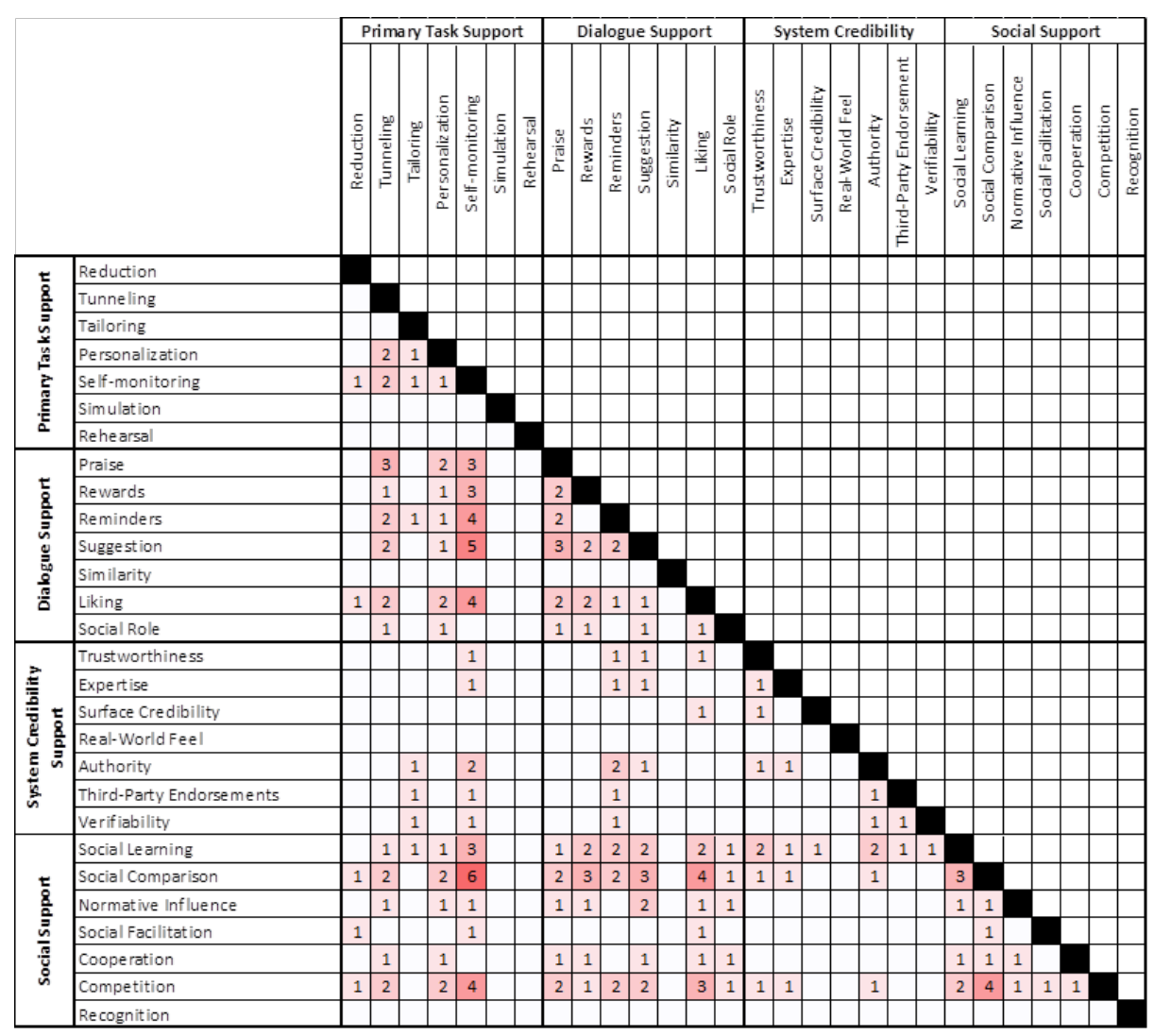

Figure 3: Heat map of persuasive features in dyad

\section{Primary Task Support}

The primary task support category includes design principles that support the carrying out of the user's primary task [10]. Primary task support features assist the user in achieving the original task for which they are using the system, in this case the act of engaging in physical activity. Self-monitoring was found to be the most widely represented primary task support feature in the articles reviewed. The majority of articles (14 out of 20) in the review included some reference to or discussion of self-monitoring features. The remaining primary task support features were represented in far fewer articles. Reduction (1 out of 20), tunneling (3 out of 20), tailoring ( 2 out of 20) and personalisation (3 out of 20) were discussed in only a small number of articles. Simulation and rehearsal were found to be absent from the articles reviewed.

Self-monitoring was found to be the most common persuasive design feature discussed in the reviewed articles. Self-monitoring was implemented in the form of manual logging [27] or automatic tracking of physical activity [30], either in terms of step count [29], distance travelled [30], active time [31] or sedentary time 
[25], or other self-evaluation criteria. A qualitative study of user's attitudes towards mobile application promoting physical activity indicated that selfmonitoring is considered to be an important tool in behaviour modification [28]. Applications incorporated the inbuilt motion sensors of the mobile device, or manual logging tools, to record the physical activity of the user. The data could then be utilised by the application to provide feedback to the user. In general, a cycle of data capture and feedback is a powerful tool in effectively persuading the user to modify their behaviour.

The reduction principle was commonly implemented through the automatic monitoring of daily step count using inbuilt motion sensors. A feature such as this can make the user aware of the physical activity that is inherent in daily activities, rather than in activities that the user would consider intentional exercise. The user can then gradually change their current behaviour to include more physical activity as part of their daily routine, such as taking the steps instead of the elevator [29].

Tunneling identified in the review included applications that provided guiding information to the user based on the individual's physical activity levels, and applications that require the user to answer a series of questions that subsequently result in the provision of recommendations based on the answers provided. For example, the user is prompted to answer a series of questions at the end of each day. The answers to these questions result in additional questions being asked or in suggestions being provided to the user that are designed to influence the user's behaviour [40].

Tailoring identified included providing tailored feedback to the user based on the data gathered from responses provided by the user [26] or data gathered via the inbuilt sensors in the device [35]. Tailoring was generally implemented in the form of tailored text content, using the personal information of the user to select appropriate health messages.

Personalisation identified in the review used the information of individual users to personalise text content and provide personalised goals to the user. The personalisation of text content was implemented by using the personal 
information of the user to create text content directed to that individual containing their personal information [26]. User goals were personalised by utilising the user's personal information, including information about the user's physical activity levels, to generate goals or targets for that individual [29].

\section{Dialogue Support}

The dialogue support category includes design principles that support humancomputer interactions in a way that users would consider to be social or interpersonal interactions. These interactions incorporate feedback to the user in the form of dialogue such as prompts, suggestions and reminder. Users are encouraged by the application and are subsequently motivated to engage in physical activity [10].

The categories of suggestions (7 out of 20), praise (5 out of 20), rewards (4 out of 20), and reminders (4 out of 20) were all found to be represented in the articles reviewed. The principle of liking (6 out of 20), which requires that the system be visually attractive in order to persuade users, was found also to be relatively well represented. The principle of social-role (1 out of 20) was discussed in only one of the articles and the principle of similarity was absent from the articles reviewed.

The implementation of praise was typically in the form of messages praising the user in response to a goal being achieved or in response to user data captured by the application. After successfully responding to a prompt by performing a physical activity, a user might receive a message praising their accomplishment [25]. Applications provided both positive and negative messages depending on the activity levels of the individual [29]. Applications provided praise to the user based on the user's response to questions asked at the end of each day [40].

Rewards were typically implemented in the form of symbolic visual rewards displayed to the user upon completion of a task or goal. Users were rewarded with a visually appealing symbols displayed on the application dashboard each time the user completed a physical activity [25]. Reward systems were implemented that encouraged users to complete physical exercise task with a series of rewards that could be progressively unlocked as the user completed exercise goals [30], or reached behaviour change milestones [33]. 
Reminders were often implemented as periodic messages sent to the user reminding them to check the application. Generic daily or weekly reminders were sent encouraging the user to continue using the application [29]. Reminders were sent to those who did not meet their goals to maintain the motivation of the user [35]. Applications that required the user to submit information such as step count at intervals used reminders to prompt the user to log their data [40].

Suggestion entails a message recommending a particular behaviour be carried out. Suggestion was used to reduce the amount of time a user remained sedentary. When inbuilt sensors detected that the user had remained sedentary for a period of time, the application prompted the user with a suggestion to engage in physical activity [25] [38] [31]. Suggestion also came in the form of motivational text suggestions [39] or video clips that provided tips or motivational messages to the user [40]. A study of the attitudes of users towards the persuasive features revealed that users may sometimes perceive suggestions to be too obtrusive to them [28].

Liking was typically implemented as presenting information or feedback in a way that was visually appealing to the user. Information was presented in a fun or light hearted way in order to engage users [29]. Applications used visually pleasing display features that allowed user feedback to be not only liked by the user, but also to convey complex information in a pleasurable way [33]. Metaphorical representations were commonly used to display the user's physical activity in a way that was intuitively understood by the user [34] [37].

Social role was implemented in one application in order to promote appropriate use of the electronic message board feature. The system posted messages using conversational language on the message board purporting to be written by users of the application [33]. Users would interpret these messages as being posted by members of the community, and as such the application can be said to be adopting a social role. The purpose was to positively influence behavioural norms within the message board. 


\section{System Credibility Support}

The system credibility support category comprises design principles that suggest the persuasive capability of a system can be improved by incorporating features that indicate to the user that the system is credible. This category was not well represented in the articles reviewed. Trustworthiness (2 out of 20), expertise (1 out of 20), authority (2 out of 20), surface credibility (1 out of 20), third-party endorsement (1 out of 20), and verifiability (1 out of 20) were each found only in a small number of articles. Real-world feel, which involves highlighting the real people behind the system content, was absent from the articles reviewed.

The trustworthiness of applications was found to be of concern to users, particularly trustworthiness in terms of accuracy of data collected by the application [28]. However, most users evaluated trustworthiness solely on the appearance of the application. Therefore, conveying trustworthiness in the visual appearance of the application is an important aspect of the design [36].

The principles of authority and expertise were also identified as a concern to users of persuasive applications. Applications that were developed by reputable sources or applications that had been developed by experts were perceived as more influential [28]. One application implemented the principle of authority in a feature that allowed users to access health information from authoritative sources [35].

Similarly to trustworthiness, the surface credibility of an application is important in gaining the trust of the user, and therefore in increasing the persuasive power of the application. As with respect to trustworthiness, users base their trust on the appearance of an application. An application having a professional or scientific appearance also can lead to an increase in surface credibility [36].

Third party endorsement is the principle that having an application endorsed by an external source, such as a well-known institution, will improve system credibility. One application implemented a third party endorsement feature that provided links to health organisations [35]. Linking to an external organisation will increase persuasiveness in two ways: by presenting a third party endorsement, and also by 
allowing users to verify the accuracy of information. Therefore, this feature also implements the principle of verifiability.

\section{Social Support}

The social support category involves persuasive design features that leverage social support to motivate users. The most frequently represented social support features were social learning (5 out of 20), social comparison (8 out of 20), and competition (5 out of 20). These features provide means to observe other users, to compare behaviour with other users, and to engage in competition with other users of the system. The remaining social support features, i.e. normative influence (2 out of 20), social facilitation (1 out of 20), and cooperation (1 out of 20), were only found in a small number of the articles reviewed. The principle of recognition which recommends providing public recognition to the user, was absent from the articles reviewed.

In the analysed works, social learning elements were implemented that allowed users to follow and view the activity information of other users that shared common interests [30]. In some cases it was implemented through message boards [33] or user profiles [35] on which users could post and share information. Social learning was perceived positively, especially with a limited group of users that shared similar goals [28]. However, in some circumstances users were not as accepting of social learning features. According to the study "the factors influencing users to take an application into use”, actually most participants did not consider social learning to be an important aspect of persuasive applications [36], and one study of user perceptions reported that some study participants were even resistant to the use of social learning features [28].

Social comparison was commonly implemented through comparing the physical activity levels of different users. For example, a feature that recorded the step count of the user and then provided feedback that compared the result to that of other users [29]. These features were implemented so that allowed users to compare activity data with individuals [31] and with group averages [33]. Interestingly, a study of "factors influencing users to take an application into use" reported about user resistance to the social comparison features, suggesting that 
such features could lead to personal embarrassment [28]. However, in another study of social context for pedometer readings, an application that included social comparison features was found to be more effective in increasing physical activity than another application without such features [41].

Competition was implemented by displaying the user's results against the results of other users $[29,37,44]$. One study of user perceptions reported that users believed competition through sharing progress with other users would be useful [28]. One application implemented a feature that incorporated both cooperation and competition by assigning users to groups that would then compete against each other [33]. In general, users that received social feedback became more competitive and engaged in higher levels of physical activity [37]. However, some evidence was also found for that individuals that competed unsuccessfully were less likely to engage in higher levels of physical activity because they felt there was no possibility of 'winning' the competition [29].

Normative influence was implemented in an application that used positive images of people performing target behaviours. The images of young adults exhibiting a desirable appearance were intended to motivate users to achieve their behaviour goals [39]. As previously discussed with regard to the principle of social role, another application featured a message board for users to post messages. In this study, messages were posted to the message board posing as users in order to promote positive norms for the group [33].

Social facilitation was implemented to promote physical activity by demonstrating that other users were performing the behaviour along with the user. One study described peer-support features allowing users to provide support to each other, such as exchanging virtual gifts with other users for reaching their goals [37].

Cooperation was implemented in one application by assigning users to groups randomly. As previously discussed with regard to competition, the group would then work together in competition against other randomly assigned groups of participants [33]. The cooperation that existed between members of the group encouraged users to adopt the target behaviour in order for their group to succeed. 
As figure 3 demonstrates self-monitoring as a persuasive feature is highly associated with social comparison. There is also a high association between the social comparison and competition. However, as the visualization is based on 20 articles, not a significant difference could be seen in the map.

\section{Limitations}

This review examined the last ten years of literature involving persuasive features in mobile applications for health education. The field of mobile and smartphone applications is a relatively recent field of exploration. As a consequence, the articles that satisfied the search criteria were typically from the last five years and the oldest article included for review was published in 2008. Articles preceding this time that were concerned with behaviour modification generally referred to technologies such as SMS mobile text messaging or other pre smartphone mobile technologies. Therefore, the selection criteria may have excluded some articles that could have yielded insight into formative persuasive technologies.

In contrast to this, it can be seen that the number of articles relating to mobile applications has been increasing. Naturally, publications that have not yet become available for review or are in the process of publication would also have been beneficial to the review. However, the time taken to complete research and publish findings means that there is a gap between the applications currently being developed and the applications evaluated in academic papers. Additionally, it is possible that the applications that are being reviewed incorporate persuasive features that are not reported in the articles.

The review is limited to articles written in English. Therefore, articles describing persuasive technologies in mobile health applications that were published in other languages were overlooked during the article selecting process. Furthermore, only one database was used during the search process. Use of additional databases could have yielded additional articles for inclusion in the review. However, major titles such as Medline, Pubmed and IEEE expolre are covered in Scopus. Scopus covers over 22,000 active titles in journals, books and conference proceedings so the reviewed covered the breadth of articles. 


\section{Conclusion}

Analysis of the available academic research into persuasive technologies used in mobile health education has revealed some interesting trends. Clearly, the most common persuasive feature implemented was self-monitoring, a feature that supports a user's primary task. In addition to this, applications frequently implemented a variety of dialogue support features and social support features. In terms of computer-human dialogue support, applications utilised user data that had been collected to persuade the user to engage in their target behaviour. A combination of praise, rewards, reminders and suggestion were used to motivate the user to achieve their goals. And yet, many applications do not take advantage of well-known and proven features. For instance, previous research has identified reminders as an important category for users to continue adherence to targeted behavior [46,47], however, not all reviewed research included the reminders as a persuasive feature. The social support features of social learning, social comparison and competition were used in combination to engage the human instinct to respond to social forces. Persuasive applications provide mechanisms for individuals to observe other peoples' behaviours, to compare their own behaviours against others, and to engage in competition with others. A system that can tap into the persuasive nature of social interaction is able to motivate individuals to achieve their target behaviour.

The most notable gap found in this review was the absence of system credibility support in most mobile applications. Although the system credibility support has been identified as one of the categories, features from this category are the least mentioned in the reviewed article, the finding of which is similar to Lehto and Oinas-Kukkonen's previous study on evaluation of six weight loss websites [48]. It has been suggested that by incorporating system credibility support features, the persuasive capability of a system will be increased. Qualitative studies have shown that features such as trustworthiness, expertise, authority, third-party endorsement, and verifiability are likely to improve the persuasiveness of a system. Better system credibility support needs to be incorporated into future persuasive mobile applications if they are to achieve the highest level of persuasiveness. 
The review indicated that persuasive categories are dependent on each other for motivating physical activity. Primary task support features such as tailoring and monitoring are often present together with dialogue support features such as reminder, rewards and praise. An example of this is "user specific goal setting” present with "text based positive reinforcement"[49]. Applications that included self-monitoring feature generally included also a feedback mechanism that allowed the user to review their data [34]. Although the persuasive features are classified under different categories, there are associations among them (cf. Figure $3)$.

In summary, developers of mobile applications should continue to incorporate persuasive principles into mobile health applications, as the contribution of this emerging technology can make to global healthcare is considerable. Randomised controlled trial results in the reviewed studies indicated the positive impact of the use of smart phone applications. This review has indicated how information systems could assist in persuading consumers to be more involved in their healthcare management. Half of the research reviewed was based on intervention studies of physical activity through mobile assistance. The focus of these studies was on intervention and outcome studies. This review identified and confirmed the effectiveness of persuasive features in physical activity studies.

\section{Appendix A}

Table A1 PSD model persuasive features [10]

\begin{tabular}{lll}
\hline Category & $\begin{array}{l}\text { Persuasive } \\
\text { feature }\end{array}$ & Definition \\
& Reduction & $\begin{array}{l}\text { System should reduce steps users take when } \\
\text { performing target behaviour }\end{array}$ \\
Task & & System should guide users in \\
& attitude/behaviour change process by providing \\
& & means for action \\
\cline { 2 - 3 } & & System should provide tailored info for user \\
& Tailoring & groups \\
\cline { 2 - 3 } & & System should offer personalized content and \\
& & services for individual users \\
\hline
\end{tabular}




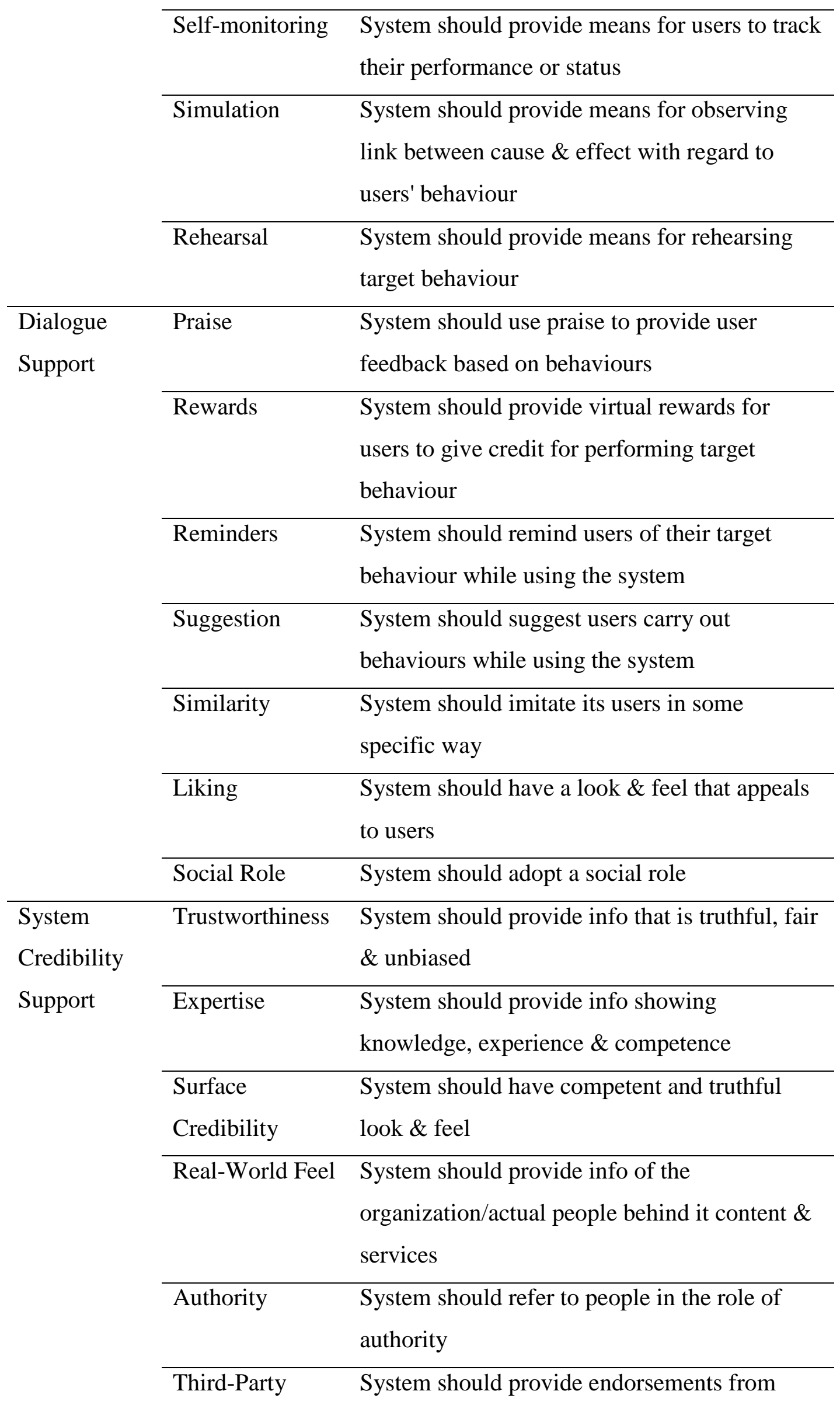




\begin{tabular}{lll}
\hline & Endorsements & external sources \\
\cline { 2 - 3 } $\begin{array}{l}\text { Supifiability } \\
\text { Support }\end{array}$ & $\begin{array}{l}\text { System should provide means to verify } \\
\text { accuracy of site content via outside sources }\end{array}$ \\
\cline { 2 - 3 } & Social Learning & $\begin{array}{l}\text { System should provide means to observe } \\
\text { others performing their target behaviours }\end{array}$ \\
\cline { 2 - 2 } & Comparison & System should provide means for comparing \\
& performance with the performance of others \\
\hline Influence & System should provide means for gathering \\
& people who have same goal \& make them feel \\
& norms \\
\hline Social & System should provide means for discerning \\
& others who are performing the behaviour \\
\hline Cooperation & System should provide means for co-operation \\
\hline Competition & System should provide means for competing \\
& with others \\
\hline Recognition & System should provide public recognition for \\
& users who perform their target behaviour \\
\hline
\end{tabular}

\section{References}

1. Garcia-Aymerich J, Lange P, Benet M, Schnohr P, Antó JM (2006) Regular physical activity reduces hospital admission and mortality in chronic obstructive pulmonary disease: a population based cohort study. Thorax 61 (9):772-778. doi:10.1136/thx.2006.060145

2. Hallal PC, Andersen LB, Bull FC, Guthold R, Haskell W, Ekelund U (2012) Global physical activity levels: surveillance progress, pitfalls, and prospects. The Lancet 380 (9838):247-257. doi:10.1016/S0140-6736(12)60646-1

3. Haskell WL, Lee I-M, Pate RR, Powell KE, Blair SN, Franklin BA, Macera CA, Heath GW, Thompson PD, Bauman A (2007) Physical activity and public health: updated recommendation for adults from the American College of Sports Medicine and the American Heart Association. Circulation 116 (9):1081-1093. doi:10.1249/mss.0b013e3180616b27

4. Lee I-M, Shiroma EJ, Lobelo F, Puska P, Blair SN, Katzmarzyk PT (2012) Effect of physical inactivity on major non-communicable diseases worldwide: an analysis of burden of disease and life expectancy. The Lancet 380 (9838):219229. doi:10.1016/S0140-6736(12)61031-9

5. Fogg BJ (2003) Persuasive technology: using computers to change what we think and do. 2003. Morgan Kaufmann,

6. Mitchell BL, Lewis NR, Smith AE, Rowlands AV, Parfitt G, Dollman J (2014) Rural Environments and Community Health (REACH): a randomised controlled 
trial protocol for an online walking intervention in rural adults. Bmc Public Health 14. doi:10.1186/1471-2458-14-969

7. Morgan PJ, Callister R, Collins CE, Plotnikoff RC, Young MD, Berry N, McElduff P, Burrows T, Aguiar E, Saunders KL (2013) The SHED-IT community trial: A randomized controlled trial of Internet- and paper-based weight loss programs tailored for overweight and obese men. Annals of Behavioral Medicine 45 (2):139-152

8. Oinas-Kukkonen H, Harjumaa M (2008) A Systematic Framework for Designing and Evaluating Persuasive Systems. In: Persuasive Technology, vol 5033. Lecture Notes in Computer Science. Springer Berlin Heidelberg, pp 164176. doi:10.1007/978-3-540-68504-3_15

9. Win KT, Hassan NM, Bonney A, Iverson D (2015) Benefits of Online Health Education: Perception from Consumers and Health Professionals. Journal of Medical Systems 39 (3). doi:10.1007/s10916-015-0224-4

10. Oinas-Kukkonen H, Harjumaa M (2009) Persuasive systems design: Key issues, process model, and system features. Communications of the Association for Information Systems 24 (1):28

11. Lehto T, Oinas-Kukkonen H (2011) Persuasive features in web-based alcohol and smoking interventions: a systematic review of the literature. Journal of Medical Internet Research 13 (3)

12. Estrin D, Sim I (2010) Open mHealth architecture: an engine for health care innovation. Science 330 (6005):759-760. doi:10.1126/science.1196187

13. Boulos MN, Wheeler S, Tavares C, Jones R (2011) How smartphones are changing the face of mobile and participatory healthcare: an overview, with example from eCAALYX. BioMedical Engineering OnLine 10 (24). doi:10.1186/1475-925X-10-24

14. Kaptein M, Markopoulos P, de Ruyter B, Aarts E (2015) Personalizing persuasive technologies: Explicit and implicit personalization using persuasion profiles. International Journal of Human-Computer Studies 77:38-51. doi:10.1016/j.ijhcs.2015.01.004

15. Win KT Implementing patient accessible health information site for diabetes management. In: Pacific Asia Conference on Information Systems, 2010. pp 1790-1797

16. Hassan NM, Win KT (2013) Exploring Design Features and Benefits of Online Patient Education (OPE) Sites for Chronic Diseases. Paper presented at the 2013 46th Hawaii International Conference on System Sciences, Hawaii, USA, January 7-10

17. Morrison LG, Yardley L, Powell J, Michie S (2012) What design features are used in effective e-health interventions? A review using techniques from Critical Interpretive Synthesis. Telemed J E Health 18 (2):137-144. doi:10.1089/tmj.2011.0062

18. Doupi P, van der Lei J (2005) Design and implementation considerations for a personalized patient education system in burn care. International Journal of Medical Informatics 74 (2-4):151-157. doi:10.1016/j.ijmedinf.2004.04.021

19. Clayman ML, Boberg EW, Makoul G (2008) The use of patient and provider perspectives to develop a patient-oriented website for women diagnosed with breast cancer. Patient education and counseling 72 (3):429-435

20. Ferney SL, Marshall AL (2006) Website physical activity interventions: preferences of potential users. Health Education Research 21 (4):560-566. doi:10.1093/her/cyl013 
21. DeGuzman MA, Ross MW (1999) Assessing the application of HIV and AIDS related education and counselling on the Internet. Patient Education and Counseling 36 (3):209-228. doi:10.1016/S0738-3991(98)00096-2

22. Gosselin P, Poitras P (2008) Use of an Internet "Viral" Marketing Software Platform in Health Promotion. Journal of Medical Internet Research 10 (4):e47. doi:10.2196/jmir.1127

23. Rezailashkajani M, Roshandel D, Ansari S, Zali MR (2008) A web-based patient education system and self-help group in Persian language for inflammatory bowel disease patients. International Journal of Medical Informatics 77 (2):122-128. doi:10.1016/j.ijmedinf.2006.12.001

24. Yamout SZ, Glick ZA, Lind DS, Monson RA, Glick PL (2011) Using social media to enhance surgeon and patient education and communication. Bulletin of the American College of Surgeons 96 (7):7-15

25. Bond DS, Thomas JG, Raynor HA, Moon J, Sieling J, Trautvetter J, Leblond T, Wing RR (2014) B-MOBILE - A Smartphone-Based Intervention to Reduce Sedentary Time in Overweight/Obese Individuals: A Within-Subjects Experimental Trial. PloS one 9 (6):e100821. doi:10.1371/journal.pone.0100821

26. Antypas K, Wangberg SC (2014) Combining Users' Needs With Health Behavior Models in Designing an Internet-and Mobile-Based Intervention for Physical Activity in Cardiac Rehabilitation. JMIR Res Protoc 3 (1):e4. doi:10.2196/resprot.2725

27. Duncan M, Vandelanotte C, Kolt GS, Rosenkranz RR, Caperchione CM, George ES, Ding H, Hooker C, Karunanithi M, Maeder AJ (2014) Effectiveness of a Web- and Mobile Phone-Based Intervention to Promote Physical Activity and Healthy Eating in Middle-Aged Males: Randomized Controlled Trial of the ManUp Study. Journal of Medical Internet Research 16 (6):e136. doi:10.2196/jmir.3107

28. Dennison L, Morrison L, Conway G, Yardley L (2013) Opportunities and Challenges for Smartphone Applications in Supporting Health Behavior Change: Qualitative Study. Journal of Medical Internet Research 15 (4):e86. doi:10.2196/jmir.2583.

29. Harries T, Eslambolchilar P, Stride C, Rettie R, Walton S (2013) Walking in the Wild - Using an Always-On Smartphone Application to Increase Physical Activity. In: Human-Computer Interaction-INTERACT 2013. Springer, pp 1936. doi:10.1007/978-3-642-40498-6_2

30. He Z, Luo Y, Liang G (2013) Runking: A mobile social persuasion system for running exercise. Paper presented at the Computing, Communications and IT Applications Conference (ComComAp), 2013, Hong Kong, April 1-4

31. Dantzig S, Geleijnse G, Halteren AT (2013) Toward a persuasive mobile application to reduce sedentary behavior. Personal and Ubiquitous Computing 17 (6):1237-1246. doi:10.1007/s00779-012-0588-0

32. Glynn LG, Hayes PS, Casey M, Glynn F, Alvarez-Iglesias A, Newell J, ÓLaighin G, Heaney D, Murphy AW (2013) SMART MOVE-a smartphonebased intervention to promote physical activity in primary care: study protocol for a randomized controlled trial. Trials 14 (157). doi:10.1186/1745-6215-14-157

33. King AC, Hekler EB, Grieco LA, Winter SJ, Sheats JL, Buman MP, Banerjee B, Robinson TN, Cirimele J (2013) Harnessing different motivational frames via mobile phones to promote daily physical activity and reduce sedentary behavior in aging adults. PLoS ONE 8 (4):e62613. doi:10.1371/journal.pone.0062613 
34. McMahon S, Vankipuram M, Fleury J (2013) Mobile computer application for promoting physical activity. Journal of gerontological nursing 39 (4):15-20. doi:10.3928/00989134-20130226-01

35. Hong Y, Dahlke DV, Ory M, Hochhalter A, Reynolds J, Purcell NP, Talwar D, Eugene N (2013) Designing iCanFit: a mobile-enabled Web application to promote physical activity for older cancer survivors. JMIR research protocols 2 (1):e12. doi:10.2196/resprot.2440

36. Chang T-R, Kaasinen E, Kaipainen K (2012) What Influences Users' Decisions to Take Apps into Use?: A Framework for Evaluating Persuasive and Engaging Design in Mobile Apps for Well-being. Paper presented at the Proceedings of the 11th International Conference on Mobile and Ubiquitous Multimedi, Ulm, Germany, December 4-6

37. Ayubi SU, Parmanto B (2012) PersonA: Persuasive social network for physical Activity. Paper presented at the Engineering in Medicine and Biology Society (EMBC), 2012 Annual International Conference of the IEEE, San Diego, CA, August 28-September 1

38. Khan AM, Siddiqi MH (2012) Promoting a healthier life-style using activityaware smart phones. Paper presented at the 2012 4th International Conference on Intelligent and Advanced Systems (ICIAS), Kuala Lumpur, June 12-14

39. Hebden L, Cook A, van der Ploeg HP, Allman-Farinelli M (2012) Development of smartphone applications for nutrition and physical activity behavior change. JMIR Research Protocols 1 (2):e9. doi:10.2196/resprot.2205

40. Fukuoka Y, Komatsu J, Suarez L, Vittinghoff E, Haskell W, Noorishad T, Pham K (2011) The mPED randomized controlled clinical trial: applying mobile persuasive technologies to increase physical activity in sedentary women protocol. BMC public health 11 (933). doi:10.1186/1471-2458-11-933

41. Foster D, Linehan C, Lawson S (2010) Motivating physical activity at work: using persuasive social media extensions for simple mobile devices. Paper presented at the 1st International Workshop on Nudge and Influence Through Mobile Devices, Lisbon, Portugal, September 7-10

42. Arteaga SM, Kudeki M, Woodworth A, Kurniawan S (2010) Mobile system to motivate teenagers' physical activity. Paper presented at the Proceedings of the 9th International Conference on Interaction Design and Children, Barcelona, Spain, June 9-12

43. Klasnja P, Consolvo S, McDonald DW, Landay JA, Pratt W (2009) Using mobile \& personal sensing technologies to support health behavior change in everyday life: lessons learned. AMIA Annual Symposium Proceedings 2009:338342

44. de Oliveira R, Oliver N (2008) TripleBeat: enhancing exercise performance with persuasion. Paper presented at the Proceedings of the 10th international conference on Human computer interaction with mobile devices and services, Amsterdam, The Netherlands, September 2-5

45. Ramaprasad A, Syn T, Win KT The bright, light, and blind/blank spots in HIPAA research: An ontological analysis. In: Proceedings of the Annual Hawaii International Conference on System Sciences, 2015. pp 3023-3032. doi:10.1109/HICSS.2015.365

46. Lappalainen $\mathrm{P}$, Langrial S, Oinas-Kukkonen H, Tolvanen A, Lappalainen R (2015) Web-Based Acceptance and Commitment Therapy for Depressive Symptoms With Minimal Support A Randomized Controlled Trial. Behavior Modification 39 (6):805-834 
47. Kuonanoja L, Langrial S, Lappalainen R, Lappalainen P, Oinas-Kukkonen H (2015) Treating Depression with a Behavior Change Support System without Face-to-Face Therapy. AIS Transactions on Human-Computer Interaction 7 (3):192-210

48. Langrial S, Oinas-Kukkonen H (2012) Less fizzy drinks: a multi-method study of persuasive reminders. Paper presented at the Proceedings of the 7th international conference on Persuasive Technology: design for health and safety, Link\&\#246;ping, Sweden,

49. King AC, Bickmore TW, Campero MI, Pruitt LA, Yin JL (2013) Employing virtual advisors in preventive care for underserved communities: Results from the COMPASS study. Journal of Health Communication 18 (12):1449-1464 